\title{
Genetic Differentiation in Species of Anopheles from the Subgenera Nyssorhynchus Based on Mitochondrial DNA
}

\author{
R. Borges-Moroni ${ }^{*}, 1$, E.C. Fraga ${ }^{3}$, J.F. Maia ${ }^{2}$, W.P. Tadei ${ }^{2}$ and J.M.M. Santos ${ }^{2}$ \\ ${ }^{1}$ Federal University of Amazonas \\ ${ }^{2}$ National Institute of Amazonian Research, Laboratory of Malaria and Dengue Vectors, Manaus, AM, Brazil \\ ${ }^{3}$ Maranhão State University, Caxias, MA, Brazil
}

\begin{abstract}
Our group analyzed species of Anopheles of the subgenus Nyssorhynchus (An. darlingi, An. marajoara, An. oswaldoi, An. benarrochi, An. triannulatus and An. rangeli) and a single species of the subgenus Anopheles (An. mattogrossensis), originating in the Amazon, based on the mitochondrial DNA control region. The fragment had $381 \mathrm{pb}$ and the nucleotide composition in A+T ranged from 85.8 to $89.5 \%$. DNA polymorphism analysis of the species detected 15 haplotypes, with the presence of 81 polymorphic loci, 95 mutations, haplotypic divergence of 0.879 , nucleotide diversity of 0.06507 , nucleotide differences pair the pair mean of 23.1749 , and the observed and expected variances of 113.840 and 8.33, respectively. The genetic distance among the Anopheles species varied from 0.06 to $1.37 \%$. An. oswaldoi and An. rangeli were the most similar, with nucleotide divergence of $0.17 \%$. The An. benarrochi populations of Ji-Paraná and Bolivia showed nucleotide divergence of $0.06 \%$. An. darlingi, An. marajoara and An. triannulatus presented nucleotide divergences of $0.35 \%$ between An. triannulatus and An. darlingiand of $0.47 \%$ between An. darlingi and An. marajoara. This data showed ample interspecific nucleotide variation, though with low nucleotide divergence. The cladogram separated the species of the subgenus Nyssorhynchus and those of the subgenera Cellia and Anopheles, with $98 \%$ bootstrap. The region control data did not show strong phylogenetic support, as indicated by the transition/transversion mean rate $(0.4643)$, which is necessary for increasing fragment size and using other more conservative genes for greater inference concerning the phylogeny of the Anopheles species of the subgenus Nyssorhynchus.
\end{abstract}

Keywords: Amazon, Anopheles, differentiation, genetic, mitochondrial DNA, Nyssorhynchus, region control.

\section{INTRODUCTION}

The Anopheles species has been studied regarding diverse aspects, since it is directly related to the transmission of malaria.

The genus Anopheles consists of 437 species, of which only a small number are important for malaria epidemiology. The genus is divided in six subgenera: Anopheles, Cellia, Nyssorhynchus, Lophopodomyia, Stethomyia and Kerteszia [1]. This classification has partially assisted in the analysis of morphological and phylogenetic similarities [2,3]. In Brazil, the principal vector species of human malaria pertains to the subgenus Nyssorhynchus that possess 29 species, among them Anopheles darlingi, which is considered the most important transmitter in the entire country, particularly in the Amazon region.

The use of techniques based on direct DNA analysis in genetic studies of the population has grown over the last decade, principally in the identification and genetic characterization of malaria vector species. Taxonomic studies of the subgenus Nyssorhynchus have revealed the existence of various complexes of the species [1]. Members of these

*Address correspondence to this author at the Depto de Parasitologia, ICB. Av. Gal Rodrigo O. J. Ramos, 3000, Coroado, Bl A, Setor Sul, Campus Universitário, 69070-000, Manaus, AM, Brazil; Tel: (92) 3305-4231; Fax: (92) 3305-4231; E-mail: borgesraquel@hotmail.com species complexes vary in vector capacity, as well as in the nature of gene flow and genetic variation, both of which are critical for explaining disease epidemiology [4]. Among the molecular markers, mitochondrial DNA (mtDNA) can reveal historical and phylogeographic patterns, rates of gene flow and can also be used to define maternal gene genealogies within species [5-8]. mtDNA is also used in genetic inter and intraspecific studies due to the great number of copies per cell, shows a faster evolution rate compared with nuclear DNA, involves predominantly maternal inherence and is small in size and therefore does not undergo genetic recombination [9], which is suitable for inferring phylogenetic relations among populations and/or species with recent time divergences due to their high mutation rate [10].

The mitochondrial genome possesses a region denominated the "control region", a non-codifying region rich in $\mathrm{A}+\mathrm{T}$ in invertebrates [11], which contains replicate initiation sites of heavy chain $(\mathrm{H})$ and transcription promoters of light and heavy chain [12], whose function is to regulate the transcription and control of DNA replication [13]. This study focused on the control region of mtDNA analysis in the subgenus Nyssorhynchus. Our aim was to test the utility of this region according to its ability to recover anopheline relationships supported by previous studies. To achieve this, we estimated the intra and interspecific genetic differentiation based on the control region of the mtDNA. 


\section{MATERIALS AND METHODOLOGY}

\section{Mosquito Collection}

Our group studied 30 individual for each species of Anopheles from different Amazonian localities (Table 1). Females were captured in the field and brought to the INPA Laboratory of Malaria Vectors in Manaus and housed individually for oviposition. Following oviposition, the females, eggs and fourth stage larvae were identified as previously described [14].

Table 1. Taxa and Collection Sites of the Seven Anopheles Species Pertaining to the Nyssorhynchus and Anopheles Subgenera of the Amazon Region. RO: Rondônia, AP: Amapá, AM: Amazonas

\begin{tabular}{|c|c|c|}
\hline Subgenera & Species & Collection Sites \\
\hline \hline Nyssorhynchus & An. oswaldoi & Ji Paraná-RO \\
\hline & An. marajoara & Macapá-AP \\
\hline & An. triannulatus & Pacoval-AP \\
\hline & An. benarrochi & Guayará Mirim-Bolívia e Ji Paraná-RO \\
\hline & An. rangeli & Ji Paraná-RO \\
\hline & An. darlingi & Timbozinho-AM \\
\hline Anopheles & An. matogrossensis & Janauari-AM \\
\hline
\end{tabular}

\section{Molecular Analyzes}

Genomic DNA was extracted individually from $4^{\text {th }}$-instar larvae, as previously described [15]. The methodology used in the maintenance of the eggs until adulthood was described by Santos et al. [16]. The primer sequences (forward and reverse) used according to a previously described method [17]. Another internal primer was designed (5' - CTA GAA TAA AAT AAT ATT AA - 3)' according to the program described by $\mathrm{Xia}$ and $\mathrm{Xie}$ [18]. The amplification was programmed for 30 cycles $\left(25 \mathrm{~s}\right.$ at $94^{\circ} \mathrm{C}, 1 \mathrm{~min}$ at 50 to $60^{\circ} \mathrm{C}$ and $1 \mathrm{~min} 10 \mathrm{~s}$ at $72^{\circ} \mathrm{C}$ ). Subsequently, polymerase chain reaction $(\mathrm{PCR})$ products were checked on $1 \%$ agarose gel electrophoresis stained with ethidium bromide and analyzed under UV light. The PCR products were purified using the protocol developed by Sanger et al. [19]. The control region sequences of mtDNA of An. gambiae and An. quadrimaculatus were taken from the GenBank, under access numbers NC 002084 and Ue5793, representing the external group, along with sequences of An. mattogrossensis obtained in this study.

\section{Statistical Analyses}

DNA sequences were aligned and nucleotide composition was calculated using ClustalW [20], included in the Bioedit [21]. The DAMBE program [18] was used to verify the presence of saturations, PAUP version 4.0b10 [22] for verifying the phylogenetic signal and Modeltest version 3.06 [23] was used to select the nucleotide substitution model. The significance of the grouping was estimated by bootstrap analysis [24]. To estimate the phylogenetic relations among the sequenced fragments of the species, we used maximum parsimony, maximum likelihood, minimum evolution and neighbor-joining assisted by PAUP. The evolutionary model for maximum likelihood was $\mathrm{HKY} 85+\mathrm{G}$, as proposed by Hasegawa et al. [25], assuming different substitution rates and with corrections for the gamma parameter and analysis of invariable sites.

\section{RESULTS}

Of the 210 sequences, we selected 42 due to the quality of the amplification, six sequences for each species. The analysis of the sequences showed 292 conserved sites of which 63 were informative for parsimony and 26 variables.

In the DNA polymorphism analysis of the species, 15 haplotypes were detected from among the 40 sequences obtained, with the presence of 81 polymorphic loci, 95 mutations, haplotypic divergence of 0.879 , nucleotide diversity of 0.06507 , nucleotide differences pair the pair mean of 23.1749 , and observed and expected variances of 113.840 and 8.33 , respectively.

The nucleotide composition of the control region showed $48.4 \%$ of adenine (A), $40.2 \%$ of thymine (T), $7.9 \%$ of cytosine $(\mathrm{C})$ and $3.9 \%$ of guanine $(\mathrm{G})$ (Table 2 ). This table shows the most elevated percentages of adenine and thymine basis in all the species analyzed $(88.6 \%)$. The highest percentage of adenine was detected in An. marajoara, while the lowest was observed in An. mattogrossensis. In relation to the thymine base, the highest percentage was verified in An. darlingi. For cytosine and thymine, the most elevated values were observed in An. mattogrossensis.

Table 2. Nucleotide Composition and Haplotypes of the Control Region of the Mitochondrial DNA of Anopheles Populations of the Subgenera Nyssorhynchus and Anopheles (A = Adenine, $\mathrm{T}=$ timine, $\mathbf{C}=$ Cytosine, $\mathbf{G}=$ Guanine). $\mathbf{B}=$ Bolivia, $\mathbf{J P}$ $=$ Ji Paraná/Rondônia. + species from GenBank

\begin{tabular}{|c|c|c|c|c|c|}
\hline Populations & $\mathbf{T}$ & $\mathbf{C}$ & $\mathbf{A}$ & $\mathbf{G}$ & Haplotypes \\
\hline An (Nys.) oswaldoi & 40.1 & 8.0 & 48.4 & 3.5 & $\mathrm{H} 1 *$ \\
\hline An. (Nys.) darlingi & 41.2 & 7.5 & 48.2 & 3.0 & $\mathrm{H} 2$ to $\mathrm{H} 4 *$ \\
\hline An. (Nys.) marajoara & 39.0 & 8.3 & 49.5 & 3.2 & $\mathrm{H} 5^{*}$ \\
\hline An. (Nys.) rangeli & 40.9 & 7.2 & 48.4 & 3.5 & H6 to $\mathrm{H} 9 *$ \\
\hline An. (Nys.) triannulatus & 41.1 & 7.5 & 48.4 & 3.0 & $\mathrm{H} 10$ and $\mathrm{H} 11^{*}$ \\
\hline An. (Nys.) benarrochi (B) & 40.2 & 7.5 & 48.8 & 3.5 & H12 and H13* \\
\hline An. (Nys.) benarrochi (JP) & 40.9 & 7.5 & 48.1 & 3.5 & H14* \\
\hline An. (Ano.) mattogrossensis & 38.2 & 9.4 & 47.6 & 4.8 & $\mathrm{H} 15^{*}$ \\
\hline Mean of populations studied & 40.2 & 7.9 & 48.4 & 3.9 & \\
\hline An. (Cel.) gambiae + & 39.1 & 7.8 & 50.3 & 2.9 & \multirow{2}{*}{$\mathrm{H} 16$ and $\mathrm{H} 17^{*}$} \\
\hline An. (Ano.) quadrimaculatus + & 40.2 & 7.7 & 48.7 & 3.4 & \\
\hline
\end{tabular}

Table 3 shows the genetic divergence values observed among the haplotypes analyzed. The nucleotide divergence varied from 0.6 to $44.2 \%$, with the shortest distance between An. rangeli and $A n$. oswaldoi $(\mathrm{D}=0.025 \%)$ and the longest between An. marajoara and An. gambiae (D $=0.442 \%)$. The 
Table 3. Matrix of Distances for the 381 pb of the Mitochondrial DNA Control Region Fragment, According to the Model HKY85+G

1- An. oswaldoi $\mathrm{H} 1$

2- An. darlingi $\mathrm{H} 20.086$

3- An. darlingi H3 0.0800 .003

4- An. darlingi $\mathrm{H} 40.0860 .0060 .003$

5- An. albitarsis H5 0.0640 .1000 .0930 .100

6- An. rangeli H6 0.0280 .0820 .0760 .0820 .053

7- An. rangeli $\mathrm{H} 70.0250 .0760 .0700 .0760 .0480 .003$

8- An. rangeli H8 0.0280 .0800 .0750 .0800 .0520 .0030 .003

9- An. rangeli $\mathrm{H} 90.0350 .1000 .0930 .1000 .0680 .0120 .0120 .009$

10- An. triannulatus H10 0.157 0.115 0.108 0.115 0.133 0.128 0.120 0.1260.151

11- An.triannulatus H11 0.1490 .1080 .1010 .1080 .1250 .1360 .1280 .1340 .1610 .003

12- An. benarrochi/Bo H12 0.052 0.103 0.097 0.103 0.078 0.0440.040 0.0430.058 0.1160.108

13- An. benarrochi/Bo H13 0.052 0.111 0.104 0.111 0.067 0.044 0.040 0.0440.058 0.1020.095 0.003

14- An. benarrochi/JI H14 0.0620 .1030 .0960 .1030 .0780 .0530 .0490 .0530 .0680 .1160 .1080 .0060 .009

15- An. matogrossensis H15 0.387 0.308 0.292 0.307 0.308 0.350 0.333 0.345 0.3890.343 0.3270.3020.3190.302

16- An. gambiae H16 0.259 0.357 0.340 0.357 0.235 0.272 0.258 0.268 0.314 0.442 0.421 0.286 0.288 0.317 0.519

17- An. quadrimaculatus H17 0.279 0.346 0.329 0.346 0.253 0.279 0.265 0.274 0.321 0.419 0.399 0.230 0.244 0.255 0.326 0.186

interpopulational nucleotide divergence observed within $A n$. benarrochi was $0.06 \%$. When compared with the nucleotide distance among the subgenera Nyssorhynchus, Anopheles and Cellia, the longest distance verified was between $A n$. gambiae and An. mattogrossensis $(\mathrm{D}=0.519)$ and the shortest between An. quadrimaculatus and An. gambiae (D = 0.186). The topologies produced by these phylogenetic methods were similar, indicating that there was an unresolved polytomous for the clade referring to the populations of An. benarrochi of Ji-Paraná and Bolivia; An. oswaldoi and $A n$. rangeli and of An. marajoara and An. darlingi. However, the clade within the subgenus Nyssorhynchus is still formed with low bootstrap values. As expected, the separation of Nyssorhynchus and Anopheles shows robust support, indicated by the bootstrap value (Fig. 1).

The topology of the consensus tree ( $50 \%$ majority rule) by the consistency index parameters $(\mathrm{CI}=0.7771)$, length in number of steps $(\mathrm{L}=167)$ and the retention index $(\mathrm{RI}=$ 0167). The heuristic search indicated by the branch-andbound manner, using equal weights for all nucleotide substitutions and including the repeated indels, generates three MP trees with 167 steps. The maximum parsimony analysis showed a separation of the subgenera Nyssorhynchus and Anopheles with moderate to strong support $(\geq 80 \%)$. In the subgenus Nyssorhynchus, the populations of An. benarrochi of Ji-Paraná and Bolivia were separated with strong support (94\%). An. darlingi and An. triannulatus were grouped in the same clade; however, this relationship was not well supported (56\%) (Fig. 1A).
The cladogram obtained by the grouping method of neighbors (Fig. 1B), using matrixes of genetic distance calculated by the Kimura model - 2 - parameters, shows that in general tree topology, the populations were allocated in three clades: the first, was made up of An. oswaldoi and An. rangeli, the second, by populations of $A n$. benarrochi and the third by An. triannulatus and An. darlingi. The generated topology also showed the separation of the subgenus Nyssorhynchus in relation to the subgenera Anopheles and Cellia with $66 \%$ bootstrap.

The cladogram obtained by the maximum likelihood (Fig. 1C) showed, in the general tree typology, that the populations of $A n$. benarrochi were also separated by $52 \%$ bootstrap support, as well as the separation of subgenus Nyssorhynchus, in relation to subgenera Cellia and Anopheles. The topology generated by the Minimum Evolution method showed that populations of An. benarrochi were separated by $66 \%$ bootstrap. An. darlingi and An. triannulatus formed a clade with $54 \%$ bootstrap and $A n$. rangeli and An. oswaldoi formed a clade with $64 \%$ bootstrap. The separation of Nyssorhynchus from the other subgenera Cellia and Anopheles was 66\% (Fig. 1D).

\section{DISCUSSION}

The control region has been used in evolutionary studies due to its evolution rate, which varies among lineages [6, 26]. In insects, mutations occur involving nucleotide substi- 


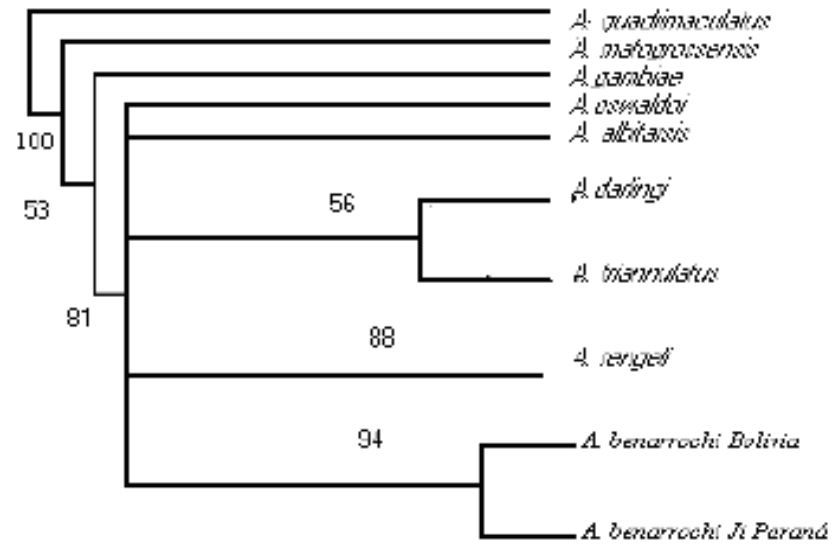

A

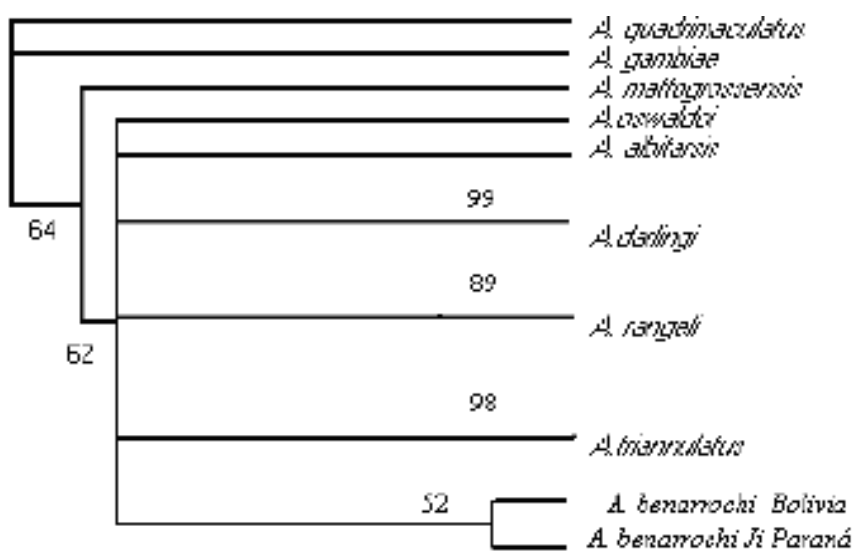

C

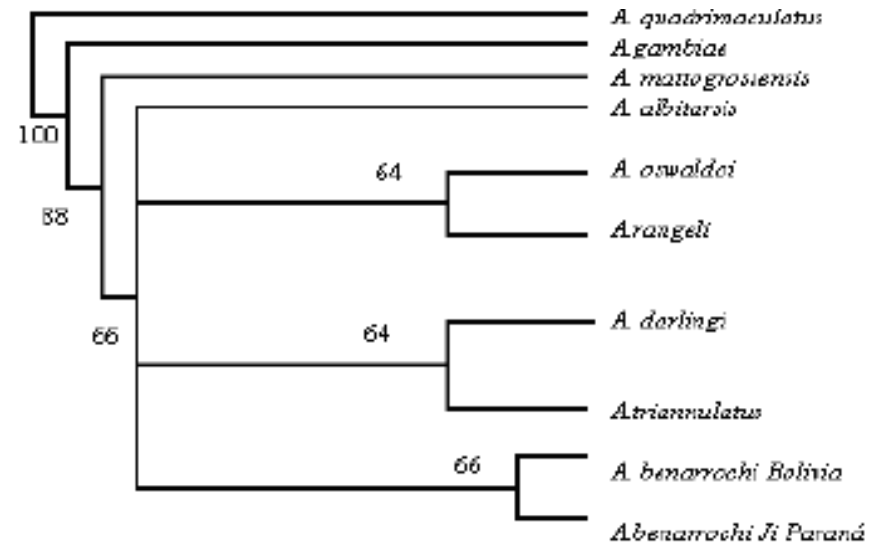

B

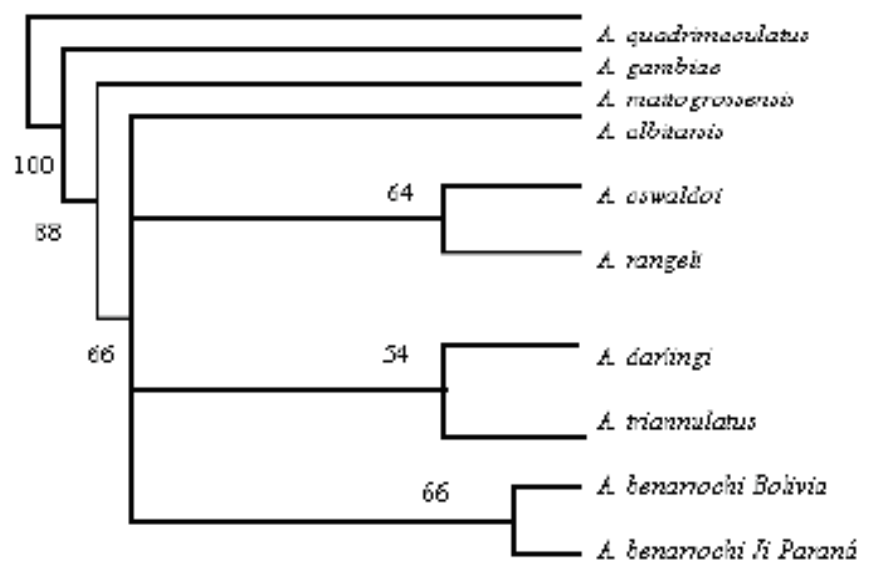

D

Fig. (1). Cladograms obtained by the Maximum-Parsimony (A), Neighbor-Joining (B), Maximum Likelihood (C), and Minimum Evolution (D), from nucleotide sequences of the control region, in the subgenus Nyssorhynchus species. The numbers are bootstrap values for 1000 replicates.

tutions, minor deletions/inversions and variations in the number of copies of repetition in tandem. Regarding the variability of the control region, it has been observed that variability is reduced in this group [27]. Thus, the data indicates that the control region in this group of mosquitos may evolve more slowly than other codification regions of the mitochondrial and nuclear DNA.

The elevated $\mathrm{A}+\mathrm{T}$ rate $(88.6 \%)$ determined for the subgenus Nyssorhynchus species reflects the greater polymorphism in the members of this subgenus. Moreno et al. reported that the nucleotide composition $(\mathrm{A}+\mathrm{T})$ of this region had shown variation [6], assuming a value of $78.1 \%$ in An. darlingi. Data obtained by Mitchell et al. [28] for An. quadrimaculatus populations of this subgenus show that the control region of the mitochondrial DNA constituted $94 \%$ $\mathrm{A}+\mathrm{T}$

Concerning the size of the control region, literature data shows variations in the different taxons. In An. gambiae and An. quadrimaculatus, this region was 520 and $625 \mathrm{pb}$, respectively $[6,28,29]$. The small size of the fragment obtained in the Anopheles species of this work and presence of regions in tandem, may have contributed to inconsistent phylogenetic inferences. Such a hypothesis was raised by
Taylor et al. when they detected $96 \% \mathrm{~A}+\mathrm{T}$ in fragments of $300 \mathrm{pb}$ in butterfly species [30]. Meanwhile, such results may be used in polymorphism and population structure studies of An. darlingi, because of the high quantity of $\mathrm{A}+\mathrm{T}$ [6].

The monophyletism of Nyssorhynchus presented low consistency across trees previously generated by methods based on characters: Maximum Parsimony (MP) and Neighbor Joining (NJ), with low bootstrap values. These results partially corroborate those observed by Krzywinski et al. [31, 32] using molecular characters. Within the subgenus Nyssorhynchus, the relations remain unclear, even though Sallum et al. [2, 33] confirmed the paraphyly of the Argyritarsis sections, which in this work are contained in $A n$. darlingi and An. marajoara, and of the Albimanus section, where An. benarrochi, An. rangeli, An. triannulatus and An. oswaldoi are allocated.

Separation among members of the Nyssorhynchus subgenus and the Cellia and Anopheles subgenera, based on the mitochondrial DNA, was also verified by Sallum et al. [2] while studying the phylogeny of the Anophelinae subfamily. Very little evidence was verified concerning the molecular data, because of the elevated number of homoplasies 
presented by the species. Homoplasies were also observed in this work. Another study by Sallum et al. [33] also confirms the data observed in our study, in which we verified the low phylogenetic signal by analyzing the mitochondrial DNA. When studying the variation in mitochondrial DNA of $A n$. rangeli and An. trinkae, Conn et al. detected a low phylogenetic signal, despite having observed the monophyletic origin of these species [34]. While studying members of the Anopheles punctulatus group using mitochondrial genomes, Beebe et al. observed little phylogenetic information [35].

Thus, the existence of so little phylogeny data that shows good phylogenetic signs in the Nyssorhynchus subgenus based on morphological, isoenzyme and DNA characters [36], allied with the almost total absence of fossil registers, has made studying the evolutional history and phylogenetic reconstruction in this subgenus difficult. Thus the data presented, based on the control region of mitochondrial DNA, is important to minimize the existing conflicts in the systematic of the group and seems promising for resolving questions relative to alpha taxonomy, beyond determining that the species studied is the result of a recent genetic divergence. However, its contribution is still minimal regarding stricter phylogenetic relations among members of the Nyssorhynchus subgenus. Similar information was reported by Foley et al. [37], who studied the phylogenetic relations and origin of the Cellia subgenus members based on the variation of sequences of the COII gene. They also found it difficult to resolve the phylogenetic relations of this subgenus. As for the Anopheles subgenus, its monophyletic group within the genus still remains obscure, due in part to the discordance among authors [2], even though Krzywinski et al. suggested the monophyly of the group [31, 32], which could corroborate data in our study.

The results generated by the distance matrix showed an elevated genetic divergence, separating the species in two large groups represented by the subgenera Nyssorhynchus and Anopheles, corroborating data obtained in several studies $[2,34,38]$. Considering the genetic distance for all species of the Nyssorhynchus subgenus, we verified that An. rangeli and An. oswaldoi were the most similar. An. gambiae and An. mattogrossensis presented an elevated genetic divergence in relation the species of the Nyssorhynchus subgenus. The four clusters formed by the genetic distance values are in agreement with Sallum et al. [33], who used molecular characters which form the group An. darlingi and $A n$. triannulatus and separated these from An. marajoara. Meanwhile, previous results obtained by Sallum et al. [2] based only on morphological characters assigned the An. marajoara and An. triannulatus groups to the same clade, placing An. darlingi in a different clade.

In relation to An. intermedius and An. mattogrossensis, which were separated from the species of the Nyssorhynchus subgenus, these results partially corroborate data presented by Sallum et al. [33], on the basis of molecular characters.

The cladograms generated for the seven Anopheles species of the Nyssorhynchus and Anopheles subgenera are in partially agreement with cladograms of these and other anophelines species, based on morphological and molecular characters [33, 39]. In general, the anophelines present an evolution with low morphological differentiation, but frequently possess genetic, physiological and chromosomic differences [40] that permit their characterization, serving as a diagnostic tool for identifying cryptic species that are very common in these groups of mosquitoes.

\section{CONCLUSION}

This data showed ample interspecific nucleotide variation, with low nucleotide divergence. The cladogram separated the species of the subgenus Nyssorhynchus and those of the subgenera Cellia and Anopheles. The region control data did not show strong phylogenetic support, which is necessary for using more conservative genes for greater inference concerning the phylogeny of species of the subgenus Nyssorhynchus.

\section{CONFLICT OF INTEREST}

The authors declare that there are no conflicts of interest.

\section{ACKNOWLEDGEMENTS}

The authors are grateful to the technicians of the Laboratory of Malaria and Dengue Vectors/INPA for identifying and collecting the mosquitoes and we thank Dr. Iracilda Sampaio and Dr. Horacio Schneider for assistance in sequences of DNA samples at the Laboratory of Genetics and Molecular Biology / Bragança / UFPA.

\section{FINANCIAL SUPPORT}

North Project of Research and Post-Graduate Studies, Institutional Research Project 3680 and National Council of Scientific and Technological Development (CNPq), and PIATAM, FAPEAM.

\section{REFERENCES}

[1] Harbach RE. Review of internal classification of the genus Anopheles (Diptera: Culicidae): the foundation for comparative systematics and phylogenetic research. Bull Entomol 1994; 84: 331-42.

[2] Sallum MAM, Schultz TR, Wilkerson RC. Phylogeny of Anophelinae (Diptera: Culicidae) based on morphological characters. Ann Entomol Soc Am 2000; 93: 745-75.

[3] Bourke BP, Nagaki SS, Bergo ES, Cardoso JC, Sallum MAM. Molecular phylogeny of the Myzorhynchella Section of Anopheles (Nyssorhynchus) (Diptera: Culicidae): genetic support for recently described and resurrected species. Mem Inst Oswaldo Cruz 2011; 106: 705-15.

[4] Tabachnick WJ, Black WC. Making a case for molecular population genetics: studies of arthropod vectors. Parasitol Today 1995; 11: 27-9.

[5] Avise JC, Helfman GS, Saunders NC, Stanton LH. Mitochondrial DNA differentiation in North Atlantic eels: Population genetic consequences of an unusual life history pattern. Proc Natl Acad Sci USA $1986 ; 83: 4350-4$.

[6] Moreno M, Marinotti O, Krzwinski J, Tadei WP, James AA, Achee $\mathrm{NL}$, et al. Complete mtDNA genomes of Anopheles darlingi and an approach to anopheline divergence time. Malaria J 2010; 9: 1-13.

[7] Bourke BP, Foster PG, Bergo ES, Calado DC, Sallum MAM. Phylogenetic relationships among species of Anopheles (Nyssorhynchus) (Diptera, Culicidae) based on nuclear and mitochondrial gene sequences. Acta Tropica 2010; 114: 88-96.

[8] Chen B, Pedro PM, Harbach RE, Somboon P, Walton C, Butlin RK. Mitochondrial DNA variation in the malaria vector Anopheles minimus across China, Thailand and Vietnam: evolutionary 
hypothesis, population structure and population history. Heredity 2011; 106: 241-52.

[9] Avise JC. Molecular Markers, Natural History and Evolution. Chapman and Hall, Inc., USA 1994.

[10] Brown WM, George MJR, Wilson AC. Rapid evolution of animal mitochondrial DNA. Proc Natl Acad Sci USA 1979; 76: 1967-71.

[11] Zhang D, Hewitt GM. Insect mitochondrial control region: a review of its structure, evolution and usefulness in evolutionary studies. Biochem Syst Ecol 1997; 25: 90-120.

[12] Strachan T, Read AP. Human molecular genetics. Oxford: Bios Scientific Publishers Ltd 1996; p. 610.

[13] Clayton DA. Replication and transcription of vertebrate mitochondrial DNA. Annu Rev Cel Biol 1991; 7: 453-78.

[14] Consoli RAGB, Lourenço-De-Oliveira R. Principais Mosquitos de Importância Sanitária no Brasil. Rio de Janeiro: Ed. Fiocruz 1994.

[15] Collins FH, Mendez MA, Rasmussen MO, Mehaffey PC, Besansky NJ, Finnerty V. A ribosomal RNA probe differentiates members of the Anopheles gambiae complex. Am J Trop Med Hyg 1987; 37: 37-41.

[16] Santos JMM, Contel EPB, Kerr WE. Biologia de anofelinos amazônicos. I. Ciclo biológico, postura e estádios larvais de Anopheles darlingi Root, 1926 (Diptera: Culicidae) da Rodovia Manaus/Boavista. Acta Amazonica 1981; 11: 789-97.

[17] Caccone A, Garcia BA, Powell JR. Evolution of the mitochondrial DNA control region in the Anopheles gambiae complex. Insect Mol Biol 1996; 5: 51-69.

[18] Xia X, Xie Z. Dambe data analysis molecular biology and evolution. J Hered 2001; 92: 371-3.

[19] Sanger F, Nicklen S, Caulson AR. DNA sequencing with chainterminating inhibitors. Proc Natl Acad Sci USA 1977; 74: 5463-7.

[20] Thompson JD, Gibson TJ, Plewniak F, Jeanmougin F, Higgins DG. The Clustal X windows interface: flexible strategies for multiple sequence alignment aided by quality analysis tools. Nucleic Acids Res 1997; 25: 4876-82.

[21] Hall TA. Bioedit: a user-friendly biological sequence alignment editor and analysis program for Windows 95/98/NT. Nucl Acids Symp Ser 1999; 41: 95-8.

[22] Swofford DL. PAUP: Phylogenetic Analysis Using Parsimony, version 3.1.1. Ilinois Natural History Survey: Champaign 1999.

[23] Posada D, Crandall KA. Modeltest: testing the model of DNA substitution. Bionformatics 1998; 14: 817-8.

[24] Felsenstein JF. Confidence limits on phylogenies: an approach using bootstrap. Evolution 1985; 38: 783-91.

[25] Hasegawa M, Kishino H, Yano T. Dating the human-ape splitting by a molecular clock of mitochondrial DNA. J Mol Evol 1985; 22: $160-74$.

[26] Caccone A, Amato GD, Powell JR. Rates and patterns of scan DNA and mtDNA divergence within the Drosophila melanogaster subgroup. Genetics 1988; 118: 671-83.

[27] Merida A, Rodriguez-Galan JM, Vincent C, Romero JM. Expression of the granule-bound starch synthase I (Waxy) gene from snapdragon is developmentally and circadian clock regulated. Plant Physiol 1999; 120: 401-10.

[28] Mitchell SE, Cockburn AF, Seawright JA. The mitochondrial genome of Anopheles quadrimaculatus species A: complete nucleotide sequence and gene organization. Genome 1993; 36: 1058-73.

[29] Beard CB, Hamm DM, Collins FH. The mitochondrial genome of the mosquito Anopheles gambiae: DNA sequence, genome organization and comparisons with mitochondrial sequences of other insects. Insect Mol Biol 1993; 2: 103-24.

[30] Taylor MFJ, Mckechnie SW, Pierce N, Kreitman M. The lepidopteran mitochondrial control region structure and evolution. Mol Biol Evol 1993; 10: 1259-72.

[31] Krzywinski J, Wilkerson RC, Besansky NJ. Evolution of mitochondrial and ribosomal gene sequences in Anophelinae (Diptera: Culicidae): Implications for phylogeny reconstruction. Mol Phylogenet Evol 2001a; 18: 479-87.

[32] Krzywinski J, Wilkerson RC, Besansky NJ. Toward understanding Anophelinae (Diptera: Culicidae) phylogeny: insights from nuclear single copy genes and the weight of evidence. Syst Biol 2001b; 50: 540-56.

[33] Sallum MAM, Schultz TR, Foster PG, Aronstein K, Wirtz RA, Wilkerson RC. Phylogeny of Anophelinae (Diptera: Culicidae) based on nuclear ribosomal and mitochondrial DNA sequences. Syst Entomol 2002; 27: 361-82.

[34] Conn JE, Mitchell SE, Cockburn AF. Mitochondrial DNA variation within and between two species of Neotropical Anopheline mosquitoes (Diptera: Culicidae). J Hered 1997; 88: 98-107.

[35] Beebe NW, Cooper RD, Morrison DA, Ellis JT. A phylogenetic study of the Anopheles punctulatus group of malaria vectors comparing rDNA gene sequence alignments derived from the mitochondrial and nuclear small ribosomal subunits. Mol Phylogenet Evol 2000; 17: 430-6.

[36] Conn J. Systematics and population level analysis of Anopheles darlingi. Mem Inst Oswaldo Cruz 1998; 93: 647-50.

[37] Foley DH, Bryan JH, Yeates D, Soul A. Evolution and Systematics of Anopheles: Insights from a molecular phylogeny of australasian mosquitoes. Mol Phylogenet Evol 1988; 9: 262-75.

[38] Collins FH, Porter CH, Cope SE. Comparison of rDNA e mtDNA in the sibling species Anopheles freeborni and Anopheles hermsi. Am J Trop Med Hyg 1990; 45: 417-23.

[39] Lounibos LP, Wilkerson RC, Conn JE, Hribar LH, Fritz GN, Danoff-Burg JA. Morphological molecular chromosomal discrimination of cryptic Anopheles (Nyssorhynchus) (Diptera: Culicidae) from South America. J Med Entomol 1998; 35: 830-8.

[40] Coluzzi M. Anopheline mosquitoes: genetics methods for species differentiation. In: Wernsdorfer WH, McGregor I, Eds. Malaria: Principles and Practise of Malariology. Edinburgh, Churchill Livingstone 1988. 